\title{
Investigating the Formation Process of Sn-Based Lead-Free Nanoparticles with a Chemical Reduction Method
}

\author{
Weipeng Zhang, ${ }^{1,2}$ Bingge Zhao, ${ }^{1,2}$ Changdong Zou, ${ }^{2}$ Qijie Zhai, \\ Yulai Gao, ${ }^{1,2,3}$ and Steve F. A. Acquah ${ }^{3}$ \\ ${ }^{1}$ Laboratory for Microstructures, Shanghai University, 99 Shangda Road, Shanghai 200436, China \\ ${ }^{2}$ School of Materials Science and Engineering, Shanghai University, 149 Yanchang Road, Shanghai 200072, China \\ ${ }^{3}$ Department of Chemistry \& Biochemistry, The Florida State University, Tallahassee, FL 32306-4390, USA \\ Correspondence should be addressed to Yulai Gao; ylgao@shu.edu.cn and Steve F. A. Acquah; sacquah@chem.fsu.edu
}

Received 22 October 2012; Revised 15 January 2013; Accepted 29 January 2013

Academic Editor: Xuedong Bai

Copyright (C) 2013 Weipeng Zhang et al. This is an open access article distributed under the Creative Commons Attribution License, which permits unrestricted use, distribution, and reproduction in any medium, provided the original work is properly cited.

\begin{abstract}
Nanoparticles of a promising lead-free solder alloy (Sn3.5Ag (wt.\%, SnAg) and Sn3.0Ag0.5Cu (wt.\%, SAC)) were synthesized through a chemical reduction method by using anhydrous ethanol and 1,10-phenanthroline as the solvent and surfactant, respectively. To illustrate the formation process of Sn-Ag alloy based nanoparticles during the reaction, X-ray diffraction (XRD) was used to investigate the phases of the samples in relation to the reaction time. Different nucleation and growth mechanisms were compared on the formation process of the synthesized nanoparticles. The XRD results revealed different reaction process compared with other researchers. There were many contributing factors to the difference in the examples found in the literature, with the main focus on the formation mechanism of crystal nuclei, the solubility and ionizability of metal salts in the solvent, the solid solubility of $\mathrm{Cu}$ in $\mathrm{Ag}$ nuclei, and the role of surfactant on the growth process. This study will help define the parameters necessary for the control of both the composition and size of the nanoparticles.
\end{abstract}

\section{Introduction}

Interconnect (solder-based) materials are of great importance in the field of electronics and manufacturing, and the most widely used solder is an $\mathrm{Sn}$-Pb-based alloy. However, the very nature of the levels of toxicity with lead in this system has been a persistent issue and is, therefore, being phased out in the electronic industry gradually. The development of viable alternatives has focused on many alloy-based systems, such as $\mathrm{Sn}-\mathrm{Cu}$ [1], Sn-Ag [2], Sn-Zn [3], Sn-Bi [4], and Sn-In [5]. To improve the properties of these binary alloy solders, a third element can be introduced. A Sn-Ag-Cu system [6] was developed to investigate this potential.

The most promising candidates for $\mathrm{Sn}-\mathrm{Pb}$ solders are $\mathrm{Sn}$ Ag-based alloys, with benefits extending towards the solderability, mechanical properties, and the reliability [7]. There are, however, some disadvantages in this system. One of them is the higher melting temperature than that of $\mathrm{Sn}-\mathrm{Pb}$ solder, which may cause some damages during the soldering process. To solve this problem, the size-dependent melting temperature of the pure melt and alloy has been studied [813]. These works show that the nanoparticles melt at a lower temperature than the corresponding bulk ones. Thus, the preparation of nanoparticles is extremely important.

Many methods have been developed to manufacture nanoparticles [14-17]. Among them, the chemical reduction method is widely used in the production of nanoparticles of lead-free solder [18-20]. There has been a significant focus on the physical properties of products. However, little work has been done on the formation process of the nanoparticles of Sn-Ag during the reaction process. The nucleation and growth mechanism are still not fully understood. Hsiao and Duh studied this issue in the synthesis process of Sn3.5Ag0.5Cu nanoparticles in aqueous solution [21]. However, their explanations about the disappearance of $\mathrm{Cu}$ in the XRD pattern are still speculative.

In this paper, nanoparticles of two promising lead-free solders, the Sn3.5Ag (wt.\%) alloy and the Sn3.0Ag0.5Cu (wt.\%) alloy, were synthesized through a chemical reduction method. We studied the formation process of nanoparticles 
TABLE 1: Synthesis parameters of SnAg nanoparticles.

\begin{tabular}{lcccccc}
\hline Sample & $\mathrm{C}_{16} \mathrm{H}_{30} \mathrm{O}_{4} \mathrm{Sn}(\mathrm{g})$ & $\mathrm{AgNO}_{3}(\mathrm{~g})$ & $\mathrm{CH}_{3} \mathrm{CH}_{2} \mathrm{OH}(\mathrm{mL})$ & $\mathrm{C}_{12} \mathrm{H}_{8} \mathrm{~N}_{2} \cdot \mathrm{H}_{2} \mathrm{O}(\mathrm{g})$ & $\mathrm{NaBH}_{4}(\mathrm{~g})$ & $\mathrm{Reaction}$ time $(\mathrm{min})$ \\
\hline SnAg1 & 0.2998 & 0.0051 & 60 & 0.2775 & 0.1892 & 15 \\
SnAg2 & 0.2998 & 0.0051 & 60 & 0.2775 & 0.1892 & 30 \\
SnAg3 & 0.2998 & 0.0051 & 60 & 0.2775 & 0.1892 & 45 \\
SnAg4 & 0.2998 & 0.0051 & 60 & 0.2775 & $0.1892 \mathrm{~g}$ & 60 \\
\hline
\end{tabular}

TABLE 2: Synthesis parameters of SAC nanoparticles.

\begin{tabular}{lccccccc}
\hline Sample & $\begin{array}{c}\mathrm{C}_{16} \mathrm{H}_{30} \mathrm{O}_{4} \mathrm{Sn} \\
(\mathrm{g})\end{array}$ & $\begin{array}{c}\mathrm{AgNO}_{3} \\
(\mathrm{~g})\end{array}$ & $\begin{array}{c}\mathrm{Cu}\left(\mathrm{OC}_{2} \mathrm{H}_{5}\right)_{2} \cdot \mathrm{H}_{2} \mathrm{O} \\
(\mathrm{g})\end{array}$ & $\begin{array}{c}\mathrm{CH}_{3} \mathrm{CH}_{2} \mathrm{OH} \\
(\mathrm{mL})\end{array}$ & $\begin{array}{c}\mathrm{C}_{12} \mathrm{H}_{8} \mathrm{~N}_{2} \cdot \mathrm{H}_{2} \mathrm{O} \\
(\mathrm{g})\end{array}$ & $\begin{array}{c}\mathrm{NaBH}_{4} \\
(\mathrm{~g})\end{array}$ & $\begin{array}{c}\mathrm{Reaction} \mathrm{time} \\
(\mathrm{min})\end{array}$ \\
\hline SAC1 & 0.3293 & 0.0047 & 0.0017 & 60 & 0.2220 & 0.1892 & 15 \\
SAC2 & 0.3293 & 0.0047 & 0.0017 & 60 & 0.2220 & 0.1892 \\
SAC3 & 0.3293 & 0.0047 & 0.0017 & 60 & 0.2220 & 0.1892 & 45 \\
SAC4 & 0.3293 & 0.0047 & 0.0017 & 60 & 0.2220 & 0.1892 \\
\hline
\end{tabular}

in an anhydrous ethanol solution during the reaction. Many experimental parameters were considered to help explain the differences in the XRD patterns found in the literature.

\section{Experimental}

The materials used to synthesize $\mathrm{Sn} 3.5 \mathrm{Ag}$ nanoparticles were tin(II) 2-ethylhexanoate $\left(\mathrm{C}_{16} \mathrm{H}_{30} \mathrm{O}_{4} \mathrm{Sn}\right)$ and silver nitrate $\left(\mathrm{AgNO}_{3}\right) .1,10$-phenanthroline $\left(\mathrm{C}_{12} \mathrm{H}_{8} \mathrm{~N}_{2} \cdot \mathrm{H}_{2} \mathrm{O}\right)$, sodium borohydride $\left(\mathrm{NaBH}_{4}\right)$, and anhydrous ethanol $\left(\mathrm{CH}_{3} \mathrm{CH}_{2} \mathrm{OH}\right)$ were selected as the surfactant, reducing agent, and solvent, respectively. In terms of the synthesis of Sn3.0Ag0.5Cu (SAC) nanoparticles, copper (II) ethoxide monohydrate $\left(\mathrm{Cu}\left(\mathrm{OC}_{2} \mathrm{H}_{5}\right)_{2} \cdot \mathrm{H}_{2} \mathrm{O}\right)$ was added to the reactant.

In a typical synthesis of $\mathrm{Sn} 3.5 \mathrm{Ag}$ nanoparticles, $0.2998 \mathrm{~g}$ of tin (II) 2-ethylhexanoate, $0.0051 \mathrm{~g}$ of silver nitrate, and $0.2775 \mathrm{~g}$ of 1,10 -phenanthroline were mixed with $60 \mathrm{~mL}$ of anhydrous ethanol to prepare the precursor solution. The mixture was stirred for about 2 hours before $0.1892 \mathrm{~g}$ of sodium borohydride was added into the stirring solution. The reaction time was the variable to be tested in the experimental procedure, so set reaction times of $15 \mathrm{~min}, 30 \mathrm{~min}, 45 \mathrm{~min}$, and $60 \mathrm{~min}$ were used. The as-synthesized nanoparticles were precipitated by a centrifuge at a rate of $4000 \mathrm{rpm}$ for $45 \mathrm{~min}$. Due to the low solubility of $\mathrm{NaBH}_{4}$ in ethanol [22], the reaction rate during the separation process was extremely low. The reduction reaction could be stopped at any predetermined time through this method. The nanoparticles obtained were rinsed 3 times with anhydrous ethanol and then dried in the vacuum chamber at $40^{\circ} \mathrm{C}$ for 8 hours. The synthesis procedure of $\mathrm{Sn} 3.0 \mathrm{Ag} 0.5 \mathrm{Cu}$ nanoparticles was similar to that of $\mathrm{Sn} 3.5 \mathrm{Ag}$ nanoparticles.

The synthesis parameters of these two lead-free nanoparticles with different reaction times were listed in Tables 1 and 2 , respectively.

The crystal structure of the synthesized SnAg alloy nanoparticles was characterized by X-ray diffraction (XRD), from $20^{\circ}$ to $90^{\circ}(2 \theta)$, using $\mathrm{Cu} K \alpha$ radiation $(\lambda=0.154056 \mathrm{~nm})$ on a Rigaku D/Max-2550 X-ray diffractometer. The electron accelerating voltage and accelerating current used in the detection process were $40 \mathrm{kV}$ and $200 \mathrm{~mA}$, respectively.

The SAC particle samples were measured on a Rigaku $\mathrm{D} / \mathrm{Max}-2200 \mathrm{X}$-ray diffractometer from $20^{\circ}$ to $90^{\circ}(2 \theta)$. The wavelength of the $\mathrm{X}$-ray from the $\mathrm{Cu} K \alpha$ radiation was $0.154056 \mathrm{~nm}$. The electron accelerating voltage and accelerating current used in the detection process were $40 \mathrm{kV}$ and $40 \mathrm{~mA}$, respectively. The surface features of the synthesized particles were studied by using a scanning electron microscope (SEM, model JSM-6700F).

\section{Results and Discussion}

3.1. Formation Process of SnAg Nanoparticles. Figure 1 shows the XRD results of the synthesized SnAg nanoparticles. There were two clear phases, the $\beta$-Sn and $\mathrm{Ag}_{3} \mathrm{Sn}$, indicating the successful alloying of Sn and Ag during the synthesis process. This was further confirmed through their crystal structures by high resolution transmission electron microscopy (HRTEM) [23]. The relative intensity of the diffraction peaks of $\beta$-Sn increased with the reaction time, while the $\mathrm{Ag}_{3} \mathrm{Sn}$ phase showed the opposite trend.

The relative intensity of the three strong peaks from the $\mathrm{Ag}_{3} \mathrm{Sn}$ phase, obtained from the XRD pattern, was shown in Figure 2. It was obvious that the relative intensity of the strongest peak declined from $100 \%$ to $10 \%$. A similar trend could be found in the other two strong peaks. It tended towards stability when the reaction time increased from $40 \mathrm{~min}$ to $60 \mathrm{~min}$.

The relative intensity of the diffraction peak of the $\mathrm{Ag}_{3} \mathrm{Sn}$ phase indicted the formation process of the two phases. When the reaction time was $15 \mathrm{~min}$, the relative intensity of the diffraction peak of the $\mathrm{Ag}_{3} \mathrm{Sn}$ phase was at the maximum. At the same time, the diffraction peak of $\beta$-Sn phase could also be found, as shown in Figure 1(a). This implied that the product was mainly in the $\mathrm{Ag}_{3} \mathrm{Sn}$ phase. When the reaction time increased to $30 \mathrm{~min}$, the relative intensity of the diffraction peak of $\mathrm{Ag}_{3} \mathrm{Sn}$ phase in the synthesized nanoparticles decreased dramatically, as shown in Figure 2. The maximum 


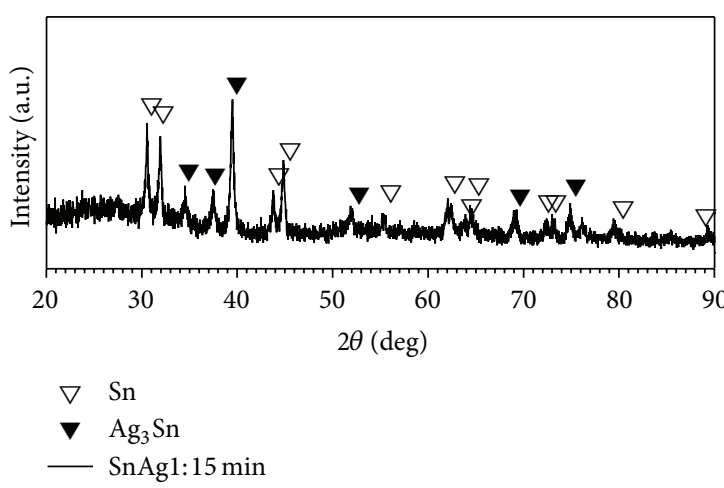

(a)

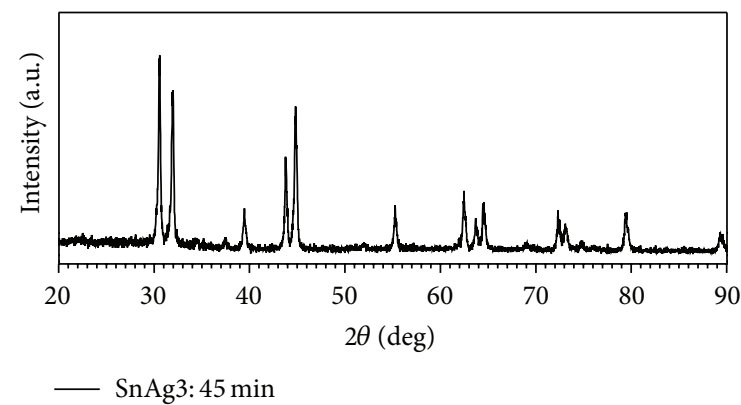

(c)

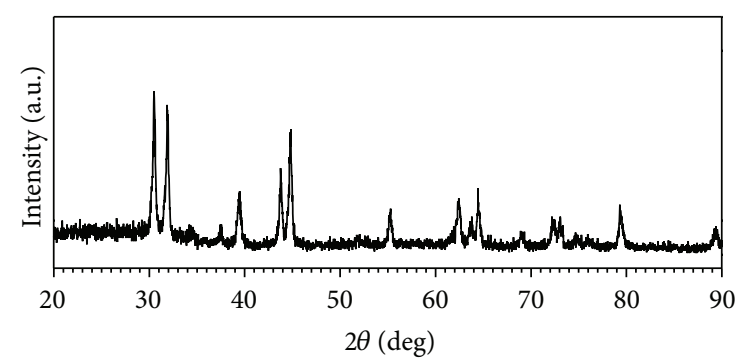

SnAg2: $30 \mathrm{~min}$

(b)

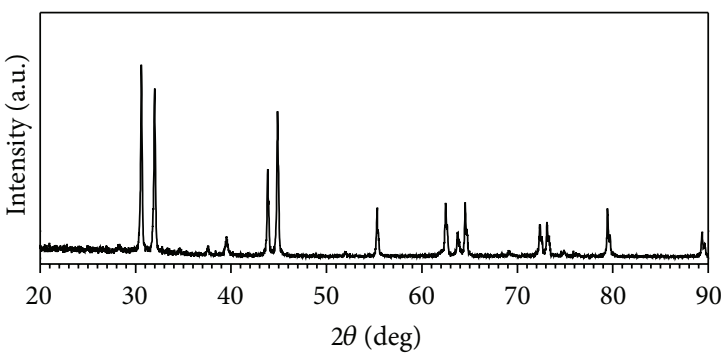

(d)

FIGURE 1: XRD pattern of the synthesized SnAg nanoparticles with different reaction times.

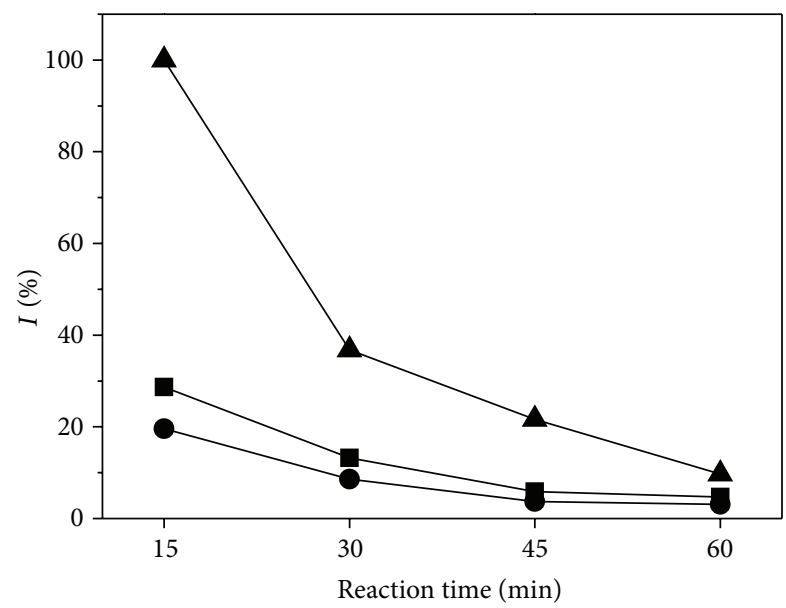

- Peak 3

$\rightarrow$ Peak 4

- Peak 5

FIGURE 2: The relative intensity of three strong peaks of the $\mathrm{Ag}_{3} \mathrm{Sn}$ phase with different reaction times.

relative intensity corresponds to the main peak of the $\beta$-Sn phase, and therefore, the amount of the $\beta$-Sn phase increased in the product. The result was the same for the nanoparticles obtained when the reaction time was further increased to $45 \mathrm{~min}$. The reaction was near completion when the reaction time was set to $60 \mathrm{~min}$ and the main phase changed to $\beta$-Sn with the relative amount of the $\mathrm{Ag}_{3} \mathrm{Sn}$ phase decreasing to a very low level, which could be derived from Figures 1 and 2 .

Hsiao and Duh [21] had studied the formation process of $\mathrm{Sn} 3.5 \mathrm{Ag} 0.5 \mathrm{Cu}$ alloy nanoparticles by means of a chemical reduction method in aqueous solution. The precursor was made by mixing $\mathrm{SnSO}_{4}, \mathrm{AgNO}_{3}$, and $\mathrm{Cu}\left(\mathrm{NO}_{3}\right) \cdot 2.5 \mathrm{H}_{2} \mathrm{O}$ together in the solvent. The reducing agent $\left(\mathrm{NaBH}_{4} / \mathrm{NaOH}\right)$ was added to the precursor and the products and reaction times were investigated. In their work, the formation process of $\mathrm{Sn} 3.5 \mathrm{Ag} 0.5 \mathrm{Cu}$ nanoparticles was divided into stages. Firstly, the $\mathrm{Ag}-\mathrm{Cu}$ nuclei formed in the solution before being transformed to $(\mathrm{Ag}, \mathrm{Cu})_{4} \mathrm{Sn}$ by adsorbing tin atoms. The second stage involved the growth of the $(\mathrm{Ag}, \mathrm{Cu})_{4} \mathrm{Sn}$ nanoparticles. It was noted that $(\mathrm{Ag}, \mathrm{Cu})_{3} \mathrm{Sn}$ formed when the tin atoms in the $(\mathrm{Ag}, \mathrm{Cu})_{4} \mathrm{Sn}$ phase exceeded the maximum amount.

Another change from the reported literature procedure was the use of anhydrous ethanol as the solvent in our experiment. There were $\mathrm{Sn}^{2+}$ and $\mathrm{Ag}^{+}$ions in the aqueous solution, and due to the different standard reduction potential of $\mathrm{Sn}^{2+} / \mathrm{Sn}^{4+}(0.151 \mathrm{~V}$ versus the standard hydrogen electrode, SHE) and $\mathrm{Ag}^{+} / \mathrm{Ag}(0.8 \mathrm{~V}$ versus SHE), the following reaction would occur [24]

$$
\mathrm{Sn}^{2+}{ }_{(\mathrm{aq})}+2 \mathrm{Ag}^{+} \longrightarrow \mathrm{Sn}^{4+}{ }_{(\mathrm{aq})}+2 \mathrm{Ag}
$$

The $(\mathrm{Ag}, \mathrm{Cu})_{4} \mathrm{Sn}$ phase could be generated without the addition of a reducing agent in reference [21]. However, the origin of Ag atoms was not specified. Using (1), it can be seen that the silver atoms came from two reaction mechanisms at the first stage. Both $\mathrm{Sn}^{2+}$ and $\mathrm{NaBH}_{4}$ could reduce $\mathrm{Ag}^{+}$. 


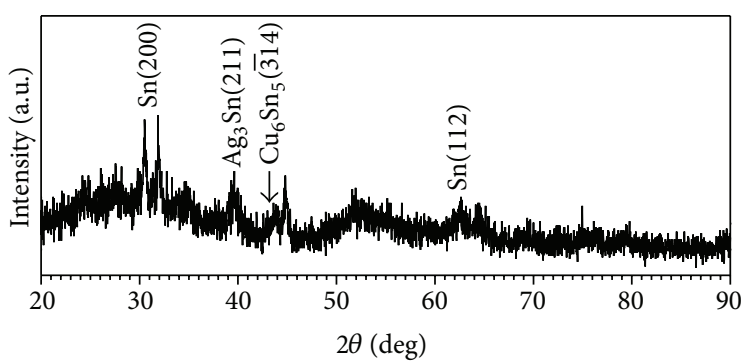

— SAC1: $15 \mathrm{~min}$

(a)

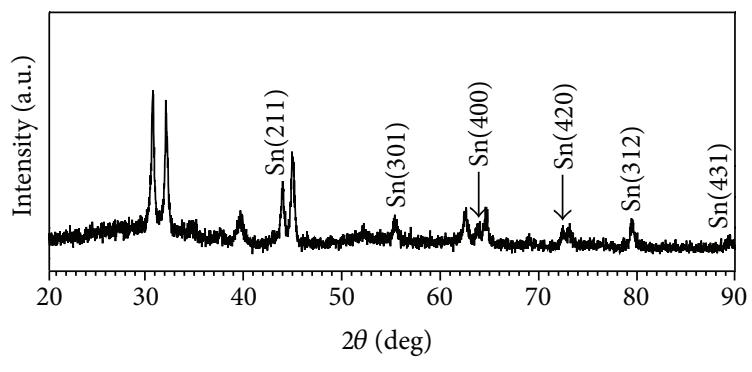

— SAC3: $45 \mathrm{~min}$

(c)

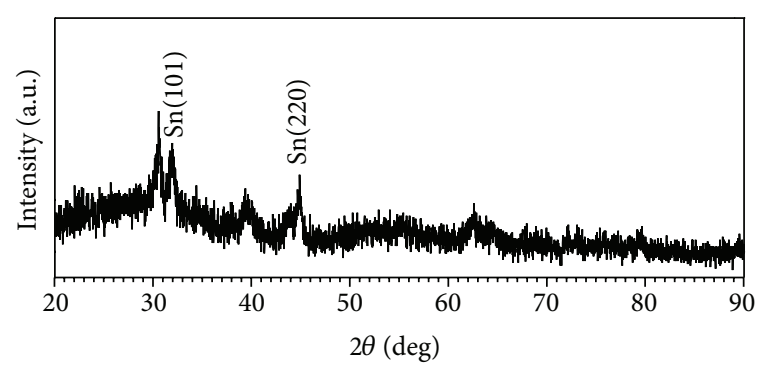

- SAC2: $30 \mathrm{~min}$

(b)

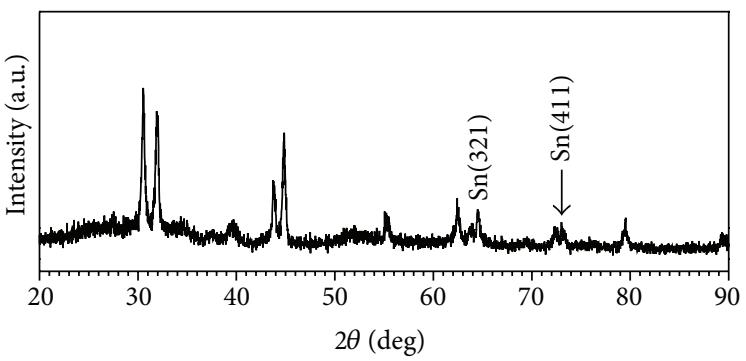

_ SAC4: $60 \mathrm{~min}$

FIGURE 3: XRD pattern of the synthesized SAC nanoparticles with different reaction times.

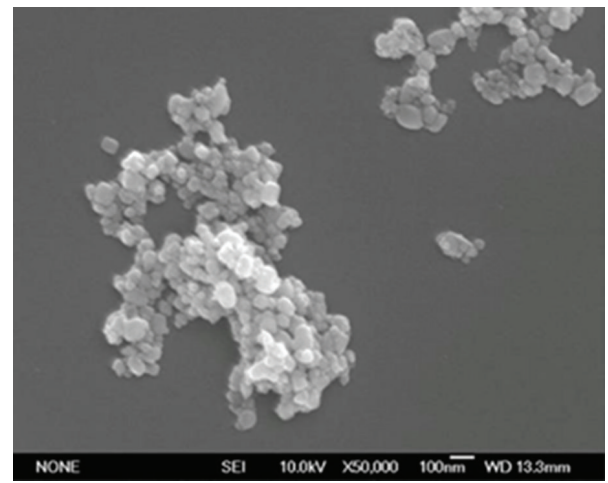

FIGURE 4: Typical SEM image of the synthesized SAC nanoparticles with a reaction time of $60 \mathrm{~min}$.

If the solvent was changed to anhydrous ethanol, which was studied in the present work, the solubility of $\mathrm{AgNO}_{3}$ would be low $[25,26]$. Although $\mathrm{AgNO}_{3}$ could be ionized in ethanol $[27,28]$, the amount was possibly small due to the difference of molecular polarity between solvent and solute. The reaction in (1) did not take place, which could be confirmed by the experimental phenomena that no change occurred during the preparation process of metal precursor.

When the reducing agent $\mathrm{NaBH}_{4}$ was added into the precursor, black particles precipitated rapidly. In the homogeneous metal ion solutions, electron transfer from $\mathrm{NaBH}_{4}$ to the metal ions occurred during the redox reaction $[29,30]$; thus the metal ions turned into atoms. This process could be described as follows [31]

$$
\begin{aligned}
2 \mathrm{Ag}^{+}+2 \mathrm{BH}_{4}{ }^{-} & \longrightarrow 2 \mathrm{Ag}+\mathrm{H}_{2}+\mathrm{B}_{2} \mathrm{H}_{6} \\
\mathrm{Sn}^{2+}+2 \mathrm{BH}_{4}{ }^{-} & \longrightarrow \mathrm{Sn}+\mathrm{H}_{2}+\mathrm{B}_{2} \mathrm{H}_{6}
\end{aligned}
$$

The transition of electrons from the reducing agent to the metal ions was determined by their standard redox potentials. The reduction rate of cations increased with the standard redox potentials increase [32]. The standard redox potential of $\mathrm{Ag} / \mathrm{Ag}^{+}$and $\mathrm{Sn} / \mathrm{Sn}^{2+}$ was $0.8 \mathrm{~V}$ (versus SHE) $[24,33]$ and $0.14 \mathrm{~V}$ (versus SHE) [34], respectively. The principles were

$$
\begin{aligned}
\mathrm{Ag}^{+}+\mathrm{e}=\mathrm{Ag} & \mathrm{E}^{0}=0.799 \mathrm{~V} \\
\mathrm{Sn}^{2+}+2 \mathrm{e}=\mathrm{Sn} & \mathrm{E}^{0}=-0.140 \mathrm{~V}
\end{aligned}
$$

It could be seen that the standard redox potential of $\mathrm{Ag} / \mathrm{Ag}^{+}$was much higher than that of $\mathrm{Sn} / \mathrm{Sn}^{2+}$. Thus, the oxidizing ability of $\mathrm{Ag}^{+}$was larger compared with $\mathrm{Sn}^{2+}$. It was the same for their reduction rate in the reaction system, which was consistent with the XRD results. Therefore, the formation process of Sn3.5Ag nanoparticles in this work could be summarized.

Before the addition of reducing agent, the metal salts were dissolved homogeneously by stirring for 2 hours in anhydrous ethanol. The potential for ionization was relatively low as the polarity was different from that of solvent.

When the reducing agent was added and mixed into the precursor, black particles precipitated immediately. At this stage, most of the $\mathrm{Ag}^{+}$ions were reduced by $\mathrm{NaBH}_{4}$. 


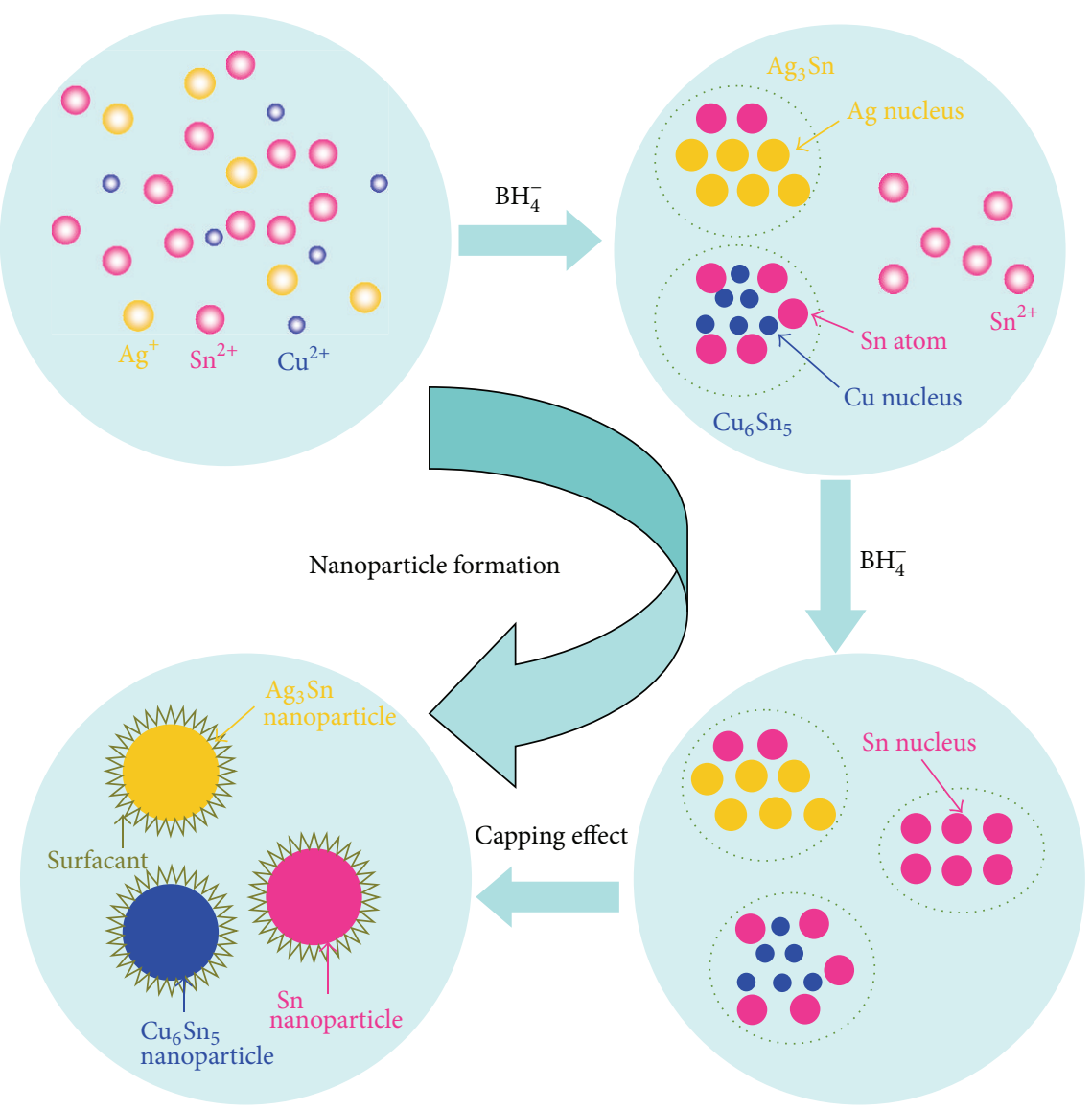

FIGURE 5: The formation process of SAC nanoparticles.

Only a few $\mathrm{Sn}^{2+}$ ions were reduced owing to the relatively lower oxidization potential and reduction rate. Silver atoms and tin atoms derived from the redox reaction formed the intermetallic compound $\left(\mathrm{Ag}_{3} \mathrm{Sn}\right)$ through the mechanical stirring. Because of the low silver content, some of the tin atoms did not combine with silver atoms and formed the $\beta$-Sn phase.

The reduction of $\mathrm{Sn}^{2+}$ ions continued till the completion of the reaction until the Sn3.5Ag alloy nanoparticles were obtained.

3.2. Formation Process of the Primary Nanoparticles of the $\mathrm{SnAgCu}$ Alloy System. The influence of $\mathrm{Cu}$ added to the $\mathrm{SnAg}$ alloy for the formation process of nanoparticles was studied in this section. Different reaction times were chosen, as shown in Table 2, and the corresponding XRD results were shown in Figure 3.

Figure 3 indicated that the products formed in the initial $15 \mathrm{~min}$ were mainly $\mathrm{Ag}_{3} \mathrm{Sn}, \mathrm{Cu}_{6} \mathrm{Sn}_{5}$, and $\beta$-Sn. Only 5 diffraction peaks of $\beta$-Sn emerged in this sample. $\mathrm{Sn}^{2+}$ ions in the solution were not sufficiently reduced at this reaction stage. After 30 minutes of reaction, the XRD pattern of the SAC2 sample showed no obvious difference with that of SAC1, except for the change in the maximum relative intensity of the $\beta$-Sn phase from (200) to (101). When the reaction duration was set to $45 \mathrm{~min}$, the diffraction peaks of $\beta$-Sn emerged, as shown in Figure 3(c). The relative intensity of the diffraction peaks of $\mathrm{Ag}_{3} \mathrm{Sn}$ and $\mathrm{Cu}_{6} \mathrm{Sn}_{5}$ decreased further. There was no significant change in the XRD patterns between SAC4, with a reaction time of $60 \mathrm{~min}$, and SAC3.

As for the $\mathrm{Sn} 3.0 \mathrm{Ag} 0.5 \mathrm{Cu}$ alloy, the standard redox potential of $\mathrm{Ag} / \mathrm{Ag}^{+}, \mathrm{Cu} / \mathrm{Cu}^{2+}$ and $\mathrm{Sn} / \mathrm{Sn}^{2+}$, was $0.8 \mathrm{~V}$ (versus SHE) $[24,33], 0.339 \mathrm{~V}$ (versus SHE) $[35,36]$, and $-0.14 \mathrm{~V}$ (versus SHE) [34], respectively. So, the oxidizing abilities of the metal cations in order were $\mathrm{Ag}^{+}, \mathrm{Cu}^{2+}$, and $\mathrm{Sn}^{2+}$. The reduction reaction of $\mathrm{Cu}^{2+}$ followed (6), and $\mathrm{Cu}$ atom formed through the electrons transmission from the reducing agent to the $\mathrm{Cu}$ cation

$$
\mathrm{Cu}^{2+}+2 \mathrm{BH}_{4}^{-} \longrightarrow \mathrm{Cu}+\mathrm{H}_{2}+\mathrm{B}_{2} \mathrm{H}_{6}
$$

It was thought that the $\mathrm{Ag}$ - $\mathrm{Cu}$ nuclei formed because the standard redox potentials of these two species were similar. The $\mathrm{Sn}$ atoms reduced in the solution adsorbed on the surface of Ag-Cu nuclei, which acted as the core, and formed a shell through the diffusion mechanism. The omission of $\mathrm{Cu}$ in the XRD pattern was explained through crystallography, which showed that the $\mathrm{Cu}$ atoms dissolved in the $\mathrm{Ag}$ matrix and formed a solid in solution.

In order to understand the origin of the difference, the synthesis conditions and the mechanism of nucleation and growth were considered. Firstly, the solubility and ionizability 
of the reactant $\mathrm{AgNO}_{3}$ in anhydrous ethanol solution were much smaller than those of aqueous solution [24-27], and that would lead to the relatively low reaction rate (the relative intensity of the XRD pattern of Sn phase was strong enough when the reaction time was 10 seconds [21], compared with that in this paper), so the metal cations could be reduced to atoms at a relatively slow rate, compared with that in aqueous solution. Secondly, $\mathrm{Ag}$ and $\mathrm{Cu}$ in their metallic form could form nuclei separately in the initial stage of the reaction. There were three main nucleation or growth mechanisms in the colloidal system. The classic Lamer mechanism [37] proposed the idea that fast nucleation and slow growth took place in the supersaturated solution. The growth process was controlled by diffusion. However, this mechanism was considered to be suitable to the sulfur sols and other analogous systems [38]. The Finke mechanism [38], which was reasonable for the unsaturated solutions, showed that nanoparticle formation was dominated by low, continuous nucleation and fast, autocatalytic surface growth. The last growth mechanism was described as the seeded growth [39]. The seeds, which act as the nuclei for the growth process, could be either the same or different composition as the absorbed atoms. This growth mechanism was used to fabricate the core-shell structures in the bimetallic alloy system [40]. In the case of the present work, when the reducing agent was added into the precursor solution, the nucleation and growth process of intermetallic compound nanoparticles could be described by the Finke mechanism.

Luo et al. synthesized $\mathrm{ZnPd}$ nanoparticles through a chemical reduction method and found that the coreduction of $\mathrm{Zn}^{2+}$ and $\mathrm{Pd}^{2+}$ could happen when the reducing agent was in excess [41]. The conditions were similar in this work, and the metal cations $\left(\mathrm{Ag}^{+}, \mathrm{Cu}^{2+}\right.$, and $\left.\mathrm{Sn}^{2+}\right)$ with different reduction potentials could be reduced simultaneously. Meanwhile, the reduction rate of $\mathrm{Ag}^{+}$and $\mathrm{Cu}^{2+}$ was faster than that of $\mathrm{Sn}^{2+}$ due to their reduction potentials [32]. There were more $\mathrm{Ag}$ and $\mathrm{Cu}$ atoms than $\mathrm{Sn}$ atoms in the solution at the initial reaction stage, and as a result of this, the coreduction of intermetallic compounds, that is, $\mathrm{Ag}_{3} \mathrm{Sn}$ and $\mathrm{Cu}_{6} \mathrm{Sn}_{5}$, could take place. Due to the relatively low content of $\mathrm{Ag}$ and $\mathrm{Cu}$, the $\mathrm{Sn}$ in the solution was not consumed in the formation process of the intermetallic phase, and the Sn phase in the XRD was made up of these Sn atoms. The growth of the formed Sn nuclei might combine the autocatalytic surface growth mechanism and homogeneous seeded growth mechanism.

In addition, the surfactant used in our experiment, which was different from that used in literature, may play an important role in the detection of $\mathrm{Cu}$. The capping effect of 1,10-phenanthroline on the formation of metal nanoparticles has already been well documented [42-53]. The passivation layer could effectively prevent the growth of the primary particles or the formation of the secondary particles, that is, aggregation and Ostwald-Ripening process [54, 55]. A typical SEM image of the SAC nanoparticles (SAC4) synthesized at room temperature with a reaction time of $60 \mathrm{~min}$ was shown in Figure 4 . The particles were basically spherical with a narrow diameter distribution of $37.6 \pm 14.9 \mathrm{~nm}$. Despite the low content of $\mathrm{Cu}$ in the core-shell structure, the relatively small particle size could make it detectable. The formation process of SAC nanoparticles was illustrated in Figure 5.

There was another question concerning whether the Ag$\mathrm{Cu}$ nuclei could actually be formed. Hume-Rothery rules were employed to prove the existence of nuclei of this specie in the literature [21]. In fact, the $\mathrm{Ag}$-Cu system was almost absolutely immiscible at room temperature, which violated the Hume-Rothery rules [56, 57]. Moreover, the lattice constant of the Ag-Cu solid solution should be smaller than that of Ag owing to the lattice contraction caused by the substitution of $\mathrm{Cu}$ atoms to Ag atoms. However, the contrary result was obtained when the $\mathrm{Ag}-\mathrm{Cu}$ nanoparticles were annealed at $300 \mathrm{~K}$ [58]. When the temperature increased to $493 \mathrm{~K}$, the diffusion of $\mathrm{Ag}$ and $\mathrm{Cu}$ was rather difficult, which indicated poor solubility [59]. A study on the equilibrium solubility of $\mathrm{Cu}$ in $\mathrm{Ag}$ showed that the substitution of a solid solution could be formed only when the samples was annealed at temperature near $653 \mathrm{~K}$ [60]. So, the Ag-Cu nuclei and the following $(\mathrm{Ag}, \mathrm{Cu})_{3} \mathrm{Sn}$ phase were not recommended considering this result. One of the possible reasons for the disappearance of $\mathrm{Cu}$ in Duh's work was the relatively large agglomeration rate of $\mathrm{Sn}$ atoms at the surface of $\mathrm{Cu}$ nuclei. The Sn shell in the nanoparticles was too thick for the $\mathrm{X}$-ray to detect the $\mathrm{Cu}$ phases. Other reasons should be taken into consideration. For example, the aggregation took place during the growth process because of the absence the surfactant acting as a protective medium.

In summary, the formation process of SAC nanoparticles could be divided into three stages, similar to that of SnAg nanoparticles. First, the metal salts were mixed in anhydrous ethanol. The mixture was intensely stirred for 2 hours to produce a uniform precursor solution. Second, black particles precipitated when the reducing agent was added into the precursor. Most of the $\mathrm{Ag}$ and $\mathrm{Cu}$ cations were reduced to their metallic form and formed nuclei, respectively. At the same time, a few Sn atoms were generated in the solution. With mechanical agitation, the nuclei of $\mathrm{Ag}$ and $\mathrm{Cu}$ acted as the heterogeneous seed, absorbed $\mathrm{Sn}$ atoms and formed the intermetallic phases, $\mathrm{Ag}_{3} \mathrm{Sn}$ and $\mathrm{Cu}_{6} \mathrm{Sn}_{5}$. The rest of the $\mathrm{Sn}$ atoms, that were not used in the formation process of the intermetallic phases could nucleate and grew into the Sn phase. The capping effect of the surfactant and the size of the synthesized nanoparticles can be well controlled. This stage can also be described by the following reaction equations:

$$
\begin{aligned}
2 \mathrm{Ag}^{+}+2 \mathrm{BH}_{4}^{-} & \longrightarrow 2 \mathrm{Ag}+\mathrm{H}_{2}+\mathrm{B}_{2} \mathrm{H}_{6} \\
\mathrm{Cu}^{2+}+2 \mathrm{BH}_{4}^{-} & \longrightarrow \mathrm{Cu}+\mathrm{H}_{2}+\mathrm{B}_{2} \mathrm{H}_{6} \\
\mathrm{Sn}^{2+}+2 \mathrm{BH}_{4}^{-} & \longrightarrow \mathrm{Sn}+\mathrm{H}_{2}+\mathrm{B}_{2} \mathrm{H}_{6} \\
\mathrm{Ag}_{(\text {reacted })}+\mathrm{Sn}_{(\text {reacted })} & \longrightarrow \mathrm{Ag}_{3} \mathrm{Sn}+\mathrm{Sn}_{(\text {unreacted })} \\
\mathrm{Cu}_{(\text {reacted) }}+\mathrm{Sn}_{\text {(reacted) }} & \longrightarrow \mathrm{Cu}_{6} \mathrm{Sn}_{5}+\mathrm{Sn}_{\text {(unreacted) }}
\end{aligned}
$$

Finally, the Sn cations in the solution continued to be reduced until the termination of the reaction, which can be described as (3). 


\section{Conclusions}

A chemical reduction method was used to synthesize leadfree alloy nanoparticles for use as a solder. The nucleation and growth mechanism in the anhydrous ethanol solution was discussed, and due to the difference in the redox potential, the $\mathrm{Ag}$ and $\mathrm{Cu}$ cations were reduced faster than $\mathrm{Sn}$ cations. The limited solubility of the reactant in the solvent ensured that the redox reaction took place. The immiscible nature of $\mathrm{Cu}$ and $\mathrm{Ag}$ at room temperature meant that these two species nucleated through the Finke mechanism separately. The nucleus acted as the heterogeneous seed during the growth process of the intermetallic compound. The nucleation mechanism of the Sn phase was similar to that of $\mathrm{Ag}$ and $\mathrm{Cu}$, while the growth followed the homogeneous seeded mechanism. Moreover, the surfactant could control the size of the synthesized nanoparticles during the growth process, through a capping effect. The relatively thin $\mathrm{Sn}$ shell surrounded the intermetallic core and the light aggregation of the primary nanoparticles made the $\mathrm{Cu}$ detectable in the XRD pattern.

\section{Acknowledgment}

This work is supported by the National Natural Science Foundation of China (Grant nos. 50971086 and 51171105).

\section{References}

[1] M. F. Arenas, M. He, and V. L. Acoff, "Effect of flux on the wetting characteristics of $\mathrm{SnAg}, \mathrm{SnCu}, \mathrm{SnAgBi}$, and $\mathrm{SnAgCu}$ lead-free solders on copper substrates," Journal of Electronic Materials, vol. 35, no. 7, pp. 1530-1536, 2006.

[2] J. H. Lee and Y. B. Park, "Abnormal failure behavior of Sn3.5Ag solder bumps under excessive electric current stressing conditions," Journal of Electronic Materials, vol. 38, no. 10, pp. 2194-2200, 2009.

[3] Y. M. Hung and C. M. Chen, "Electromigration of Sn-9wt.\%Zn solder," Journal of Electronic Materials, vol. 37, no. 6, pp. 887-893, 2008.

[4] F. Guo, G. Xu, H. He, M. Zhao, J. Sun, and C. H. Wang, "Effect of electromigration and isothermal aging on the formation of metal whiskers and hillocks in eutectic Sn-Bi solder joints and reaction films," Journal of Electronic Materials, vol. 38, no. 12, pp. 2647-2658, 2009.

[5] H. Y. Guo, J. D. Guo, and J. K. Shang, "Influence of thermal cycling on the thermal resistance of solder interfaces," Journal of Electronic Materials, vol. 38, no. 12, pp. 2470-2478, 2009.

[6] I. Ohnuma, M. Miyashita, K. Anzai et al., "Phase equilibria and the related properties of $\mathrm{Sn}-\mathrm{Ag}$-Cu based $\mathrm{Pb}$-free solder alloys," Journal of Electronic Materials, vol. 29, no. 10, pp. 1137-1144, 2000.

[7] T. Siewert, S. Liu, D. R. Smith, and J. C. Madeni, "Database for solder properties with emphasis on new lead-free solders," NIST \& Colorado School of Mines, Release, vol. 4, 2002.

[8] P. Buffat and J. P. Borel, "Size effect on the melting temperature of gold particles," Physical Review A, vol. 13, no. 6, pp. 22872298, 1976.

[9] W. A. Jesser, G. J. Shiflet, G. L. Allen, and J. L. Crawford, "Equilibrium phase diagrams of isolated nano-phases," Materials Research Innovations, vol. 2, no. 4, pp. 211-216, 1999.
[10] J. Lee, J. Lee, T. Tanaka, H. Mori, and K. Penttilä, "Phase diagrams of nanometer-sized particles in binary systems," Journal of Management, vol. 57, no. 3, pp. 56-59, 2005.

[11] M. Lučić Lavčević and Z. Ogorelec, "Melting and solidification of Sn-clusters," Materials Letters, vol. 57, pp. 4134-4139, 2003.

[12] C. R. M. Wronski, "The size dependence of the melting point of small particles of tin," British Journal of Applied Physics, vol. 18, no. 12, pp. 1731-1737, 1967.

[13] W. A. Jesser, R. Z. Shneck, and W. W. Gile, "Solid-liquid equilibria in nanoparticles of Pb-Bi alloys," Physical Review B, vol. 69, no. 14, Article ID 144121, 2004.

[14] J. S. Benjamin, "Dispersion strengthened superalloys by mechanical alloying," Metallurgical Transactions, vol. 1, no. 10, pp. 2943-2951, 1970.

[15] R. Birringer, H. Gleiter, H. P. Klein, and P. Marquardt, "Nanocrystalline materials an approach to a novel solid structure with gas-like disorder?” Physics Letters A, vol. 102, no. 8, pp. 365-369, 1984.

[16] I. T. H. Chang and Z. Ren, "Simple processing method and characterisation of nanosized metal powders," Materials Science and Engineering A, vol. 375-377, no. 1-2, pp. 66-71, 2004.

[17] C. H. Bernard Ng, J. Yang, and W. Y. Fan, "Synthesis and selfassembly of one-dimensional sub-10 nm Ag nanoparticles with cyclodextrin," Journal of Physical Chemistry C, vol. 112, no. 11, pp. 4141-4145, 2008.

[18] H. J. Jiang, K. S. Moon, and C. P. Wong, “Tin/silver/copper alloy nanoparticle pastes for low temperature lead-free interconnect applications," in Proceedings of the 58th Electronic Components and Technology Conference (ECTC '08), pp. 1400-1404, May 2008.

[19] L. Y. Hsiao and J. G. Duh, "Synthesis and characterization of lead-free solders with $\mathrm{Sn}-3.5 \mathrm{Ag}-\mathrm{xCu}(\mathrm{x}=0.2,0.5,1.0)$ alloy nanoparticles-by the chemical reduction method," Journal of the Electrochemical Society, vol. 152, no. 9, pp. J105-J109, 2005.

[20] H. Jiang, K. S. Moon, F. Hua, and C. P. Wong, "Synthesis and thermal and wetting properties of tin/silver alloy nanoparticles for low melting point lead-free solders," Chemistry of Materials, vol. 19, no. 18, pp. 4482-4485, 2007.

[21] L. Y. Hsiao and J. G. Duh, "Revealing the nucleation and growth mechanism of a novel solder developed from Sn-3.5Ag$0.5 \mathrm{Cu}$ nanoparticles by a chemical reduction method," Journal of Electronic Materials, vol. 35, no. 9, pp. 1755-1760, 2006.

[22] X. Yang, Q. Wang, Y. Tao, and H. Xu, "A modified method to prepare diselenides by the reaction of selenium with sodium borohydride," Journal of Chemical Research, no. 4, pp. 160-161, 2002.

[23] C. Zou, Y. Gao, B. Yang, and Q. Zhai, "Nanoparticles of Sn3.0Ag0.5Cu alloy synthesized at room temperature with large melting temperature depression," Journal of Materials Science, pp. 1-6, 2011.

[24] W. Lee, R. Scholz, K. Nielsch, and U. Gösele, "A template-based electrochemical method for the synthesis of multisegmented metallic nanotubes," Angewandte Chemie, vol. 44, no. 37, pp. 6050-6054, 2005.

[25] C. Wang, X. Zhang, X. Qian, W. Wang, and Y. Qian, "Ultrafine powder of silver sulfide semiconductor prepared in alcohol solution," Materials Research Bulletin, vol. 33, no. 7, pp. 10831086, 1998.

[26] X. F. Qian, J. Yin, S. Feng, S. H. Liu, and Z. K. Zhu, "Preparation and characterization of polyvinylpyrrolidone films containing silver sulfide nanoparticles," Journal of Materials Chemistry, vol. 11, no. 10, pp. 2504-2506, 2001. 
[27] A. Y. Robin, J. L. Sagué, and K. M. Fromm, "On the coordination behaviour of $\mathrm{NO}_{3}^{-}$in coordination compounds with $\mathrm{Ag}^{+}$: part 1 . Solubility effect on the formation of coordination polymer networks between $\mathrm{AgNO}_{3}$ and $\mathrm{L}$ ( $\mathrm{L}=$ ethanediyl bis(isonicotinate) as a function of solvent," CrystEngComm, vol. 8, no. 5, pp. 403416, 2006.

[28] M. Szymańska-Chargot, A. Gruszecka, A. Smolira et al., "Formation of nanoparticles and nanorods via UV irradiation of $\mathrm{AgNO}_{3}$ solutions," Journal of Alloys and Compounds, vol. 486, no. 1-2, pp. 66-69, 2009.

[29] A. Corrias, G. Ennas, G. Licheri, G. Marongiu, and G. Paschina, "Amorphous metallic powders prepared by chemical reduction of metal ions with potassium borohydride in aqueous solution," Chemistry of Materials, vol. 2, no. 4, pp. 363-366, 1990.

[30] D. Zeng and M. J. Hampden-Smith, "Synthesis and characterization of nanophase group 6 metal $(\mathrm{M})$ and metal carbide (M2C) powders by chemical reduction methods," Chemistry of Materials, vol. 5, no. 5, pp. 681-689, 1993.

[31] L. Mulfinger, S. D. Solomon, M. Bahadory, A. V. Jeyarajasingam, S. A. Rutkowsky, and C. Boritz, "Synthesis and study of silver nanoparticles," Journal of Chemical Education, vol. 84, pp. 322325, 2007.

[32] R. G. Reifler and B. F. Smets, "Enzymatic reduction of 2,4,6trinitrotoluene and related nitroarenes: kinetics linked to oneelectron redox potentials," Environmental Science and Technology, vol. 34, no. 18, pp. 3900-3906, 2000.

[33] O. S. Ivanova and F. P. Zamborini, "Size-dependent electrochemical oxidation of silver nanoparticles," Journal of the American Chemical Society, vol. 132, no. 1, pp. 70-72, 2010.

[34] M. M. P. Janssen and J. Moolhuysen, "State and action of the tin atoms in platinum-tin catalysts for methanol fuel cells," Journal of Catalysis, vol. 46, no. 3, pp. 289-296, 1977.

[35] F. Kooli, V. Rives, and W. Jones, "Reduction of $\mathrm{Ni}^{2+}-\mathrm{Al}^{3+}$ and $\mathrm{Cu}^{2+}-\mathrm{Al}^{3+}$ layered double hydroxides to metallic $\mathrm{Ni}^{0}$ and $\mathrm{Cu}^{0}$ via polyol treatment," Chemistry of Materials, vol. 9, no. 10, pp. 2231-2235, 1997.

[36] R. Qiu, X. L. Zhang, R. Qiao, Y. Li, Y. I. Kim, and Y. S. Kang, "CuNi dendritic material: synthesis, mechanism discussion, and application as glucose sensor," Chemistry of Materials, vol. 19, no. 17, pp. 4174-4180, 2007.

[37] V. K. Lamer and R. H. Dinegar, "Theory, production and mechanism of formation of monodispersed hydrosols," Journal of the American Chemical Society, vol. 72, no. 11, pp. 4847-4854, 1950.

[38] M. A. Watzky and R. G. Finke, "Transition metal nanocluster formation kinetic and mechanistic studies. A new mechanism when hydrogen is the reductant: slow, continuous nucleation and fast autocatalytic surface growth," Journal of the American Chemical Society, vol. 119, no. 43, pp. 10382-10400, 1997.

[39] H. Yu, P. C. Gibbons, K. F. Kelton, and W. E. Buhro, "Heterogeneous seeded growth: a potentially general synthesis of monodisperse metallic nanoparticles," Journal of the American Chemical Society, vol. 123, no. 37, pp. 9198-9199, 2001.

[40] G. Schmid, H. West, J. O. Malm, J. O. Bovin, and C. Grenthe, "Catalytic properties of layered gold-palladium colloids," Angewandte Chemie, vol. 35, no. 17, pp. 1099-1103, 1996.

[41] Y. Luo, Y. Sun, U. Schwarz, and M. Armbrüster, "Systematic exploration of synthesis pathways to nanoparticulate $\mathrm{ZnPd}$," Chemistry of Materials, vol. 24, pp. 3094-3100, 2012.

[42] W. W. Brandt, F. P. Dwyer, and E. C. Gyarfas, "Chelate complexes of 1,10-phenanthroline and related compounds," Chemical Reviews, vol. 54, no. 6, pp. 959-1017, 1954.
[43] J. Ferguson, C. J. Hawkins, N. A. P. Kane-Maguire, and H. Lip, "Absolute configurations of 1,10-phenanthroline and 2,21bipyridine metal complexes," Inorganic Chemistry, vol. 8, no. 4, pp. 771-779, 1969.

[44] J. Gallagher, C. H. B. Chen, C. Q. Pan, D. M. Perrin, Y. M. Cho, and D. S. Sigman, "Optimizing the targeted chemical nuclease activity of 1,10- phenanthroline-copper by ligand modification," Bioconjugate Chemistry, vol. 7, no. 4, pp. 413-420, 1996.

[45] N. H. Jang, J. S. Suh, and M. Moskovits, "Effect of surface geometry on the photochemical reaction of 1,10-phenanthroline adsorbed on silver colloid surfaces," Journal of Physical Chemistry B, vol. 101, no. 41, pp. 8279-8285, 1997.

[46] M. C. Lim, E. Sinn, and R. B. Martin, "Crystal structure of a mixed-ligand complex of copper(II), 1,10-phenanthroline, and glycylglycine dianion: glycylglycinato(1,10-phenanthroline)copper(II) trihydrate," Inorganic Chemistry, vol. 15, no. 4, pp. 807-811, 1976.

[47] M. Muniz-Miranda, "Surface enhanced Raman scattering and normal coordinate analysis of 1,10-phenanthroline adsorbed on silver sols," Journal of Physical Chemistry A, vol. 104, no. 33, pp. 7803-7810, 2000.

[48] C. Pettinari, M. Pellei, M. Miliani et al., "Tin(IV) and organotin(IV) complexes containing mono or bidentate N-donor ligands : III.1 1-methylimidazole derivatives: synthesis, spectroscopic and structural characterization," Journal of Organometallic Chemistry, vol. 553, no. 1-2, pp. 345-369, 1998.

[49] S. Sarkar, M. Pradhan, A. K. Sinha, M. Basu, and T. Pal, "Chelate effect in surface enhanced Raman scattering with transition metal nanoparticles," The Journal of Physical Chemistry Letters, vol. 1, no. 1, pp. 439-444, 2010.

[50] D. S. Sigman, "Nuclease activity of 1,10-phenanthroline-copper ion," Accounts of Chemical Research, vol. 19, no. 6, pp. 180-186, 1986.

[51] Y. Wang and J. Y. Lee, "Molten salt synthesis of tin oxide nanorods: morphological and electrochemical features," Journal of Physical Chemistry B, vol. 108, no. 46, pp. 17832-17837, 2004.

[52] Y. Wang, J. Y. Lee, and T. C. Deivaraj, "Controlled synthesis of V-shaped $\mathrm{SnO}_{2}$ nanorods," Journal of Physical Chemistry B, vol. 108, no. 36, pp. 13589-13593, 2004.

[53] C. Yoon, M. D. Kuwabara, A. Spassky, and D. S. Sigman, "Sequence specificity of the deoxyribonuclease activity of 1,10phenanthroline-copper ion," Biochemistry, pp. 2116-2121, 1990.

[54] I. M. Lifshitz and V. V. Slyozov, "The kinetics of precipitation from supersaturated solid solutions," Journal of Physics and Chemistry of Solids, vol. 19, no. 1-2, pp. 35-50, 1961.

[55] C. Wagner, "Theorie der alterung von niederschlägen durch umlösen (Ostwald-Reifung)," Zeitschrift Für Elektrochemie, Berichte Der Bunsengesellschaft Für Physikalische Chemie, vol. 65, pp. 581-591, 1961.

[56] H. W. Sheng, G. Wilde, and E. Ma, "The competing crystalline and amorphous solid solutions in the Ag-Cu system," Acta Materialia, vol. 50, no. 3, pp. 475-488, 2002.

[57] P. R. Subramanian and J. H. Perepezko, "The ag-cu (silvercopper) system," Journal of Phase Equilibria, vol. 14, no. 1, pp. 62-75, 1993.

[58] M. Hirai and A. Kumar, "Wavelength tuning of surface plasmon resonance by annealing silver-copper nanoparticles," Journal of Applied Physics, vol. 100, no. 1, Article ID 014309, 2006.

[59] S. J. Kim, E. A. Stach, and C. A. Handwerker, "Fabrication of conductive interconnects by Ag migration in $\mathrm{Cu}$-Ag core-shell nanoparticles," Applied Physics Letters, vol. 96, no. 14, Article ID 144101, 2010. 
[60] Y. I. Vesnin and Y. V. Shubin, "Equilibrium solid solubilities in the Ag-Cu system by X-ray diffractometry," Journal of Physics F, vol. 18, no. 11, pp. 2381-2386, 1988. 

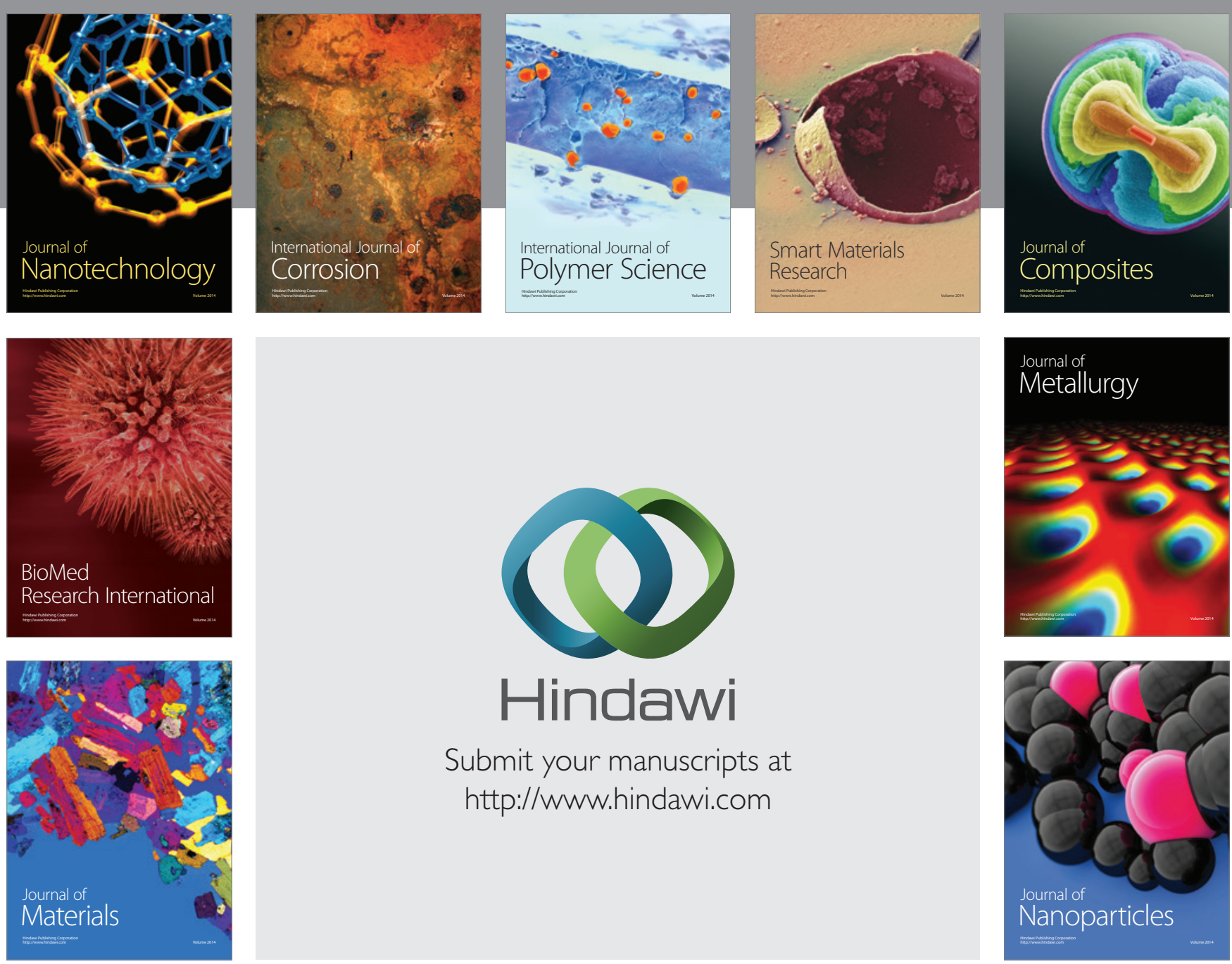

Submit your manuscripts at http://www.hindawi.com
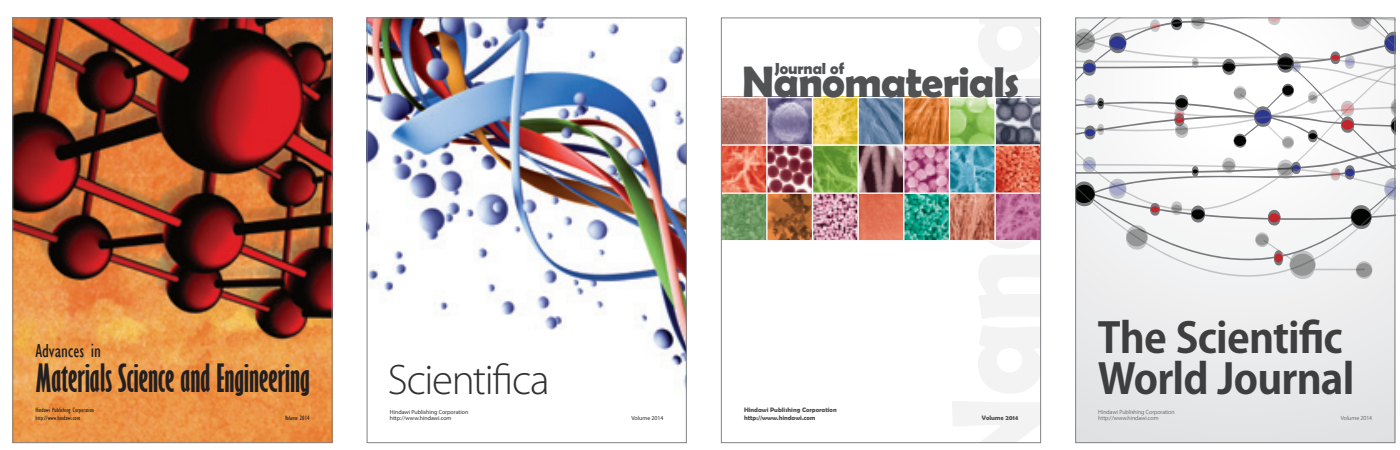

\section{The Scientific World Journal}
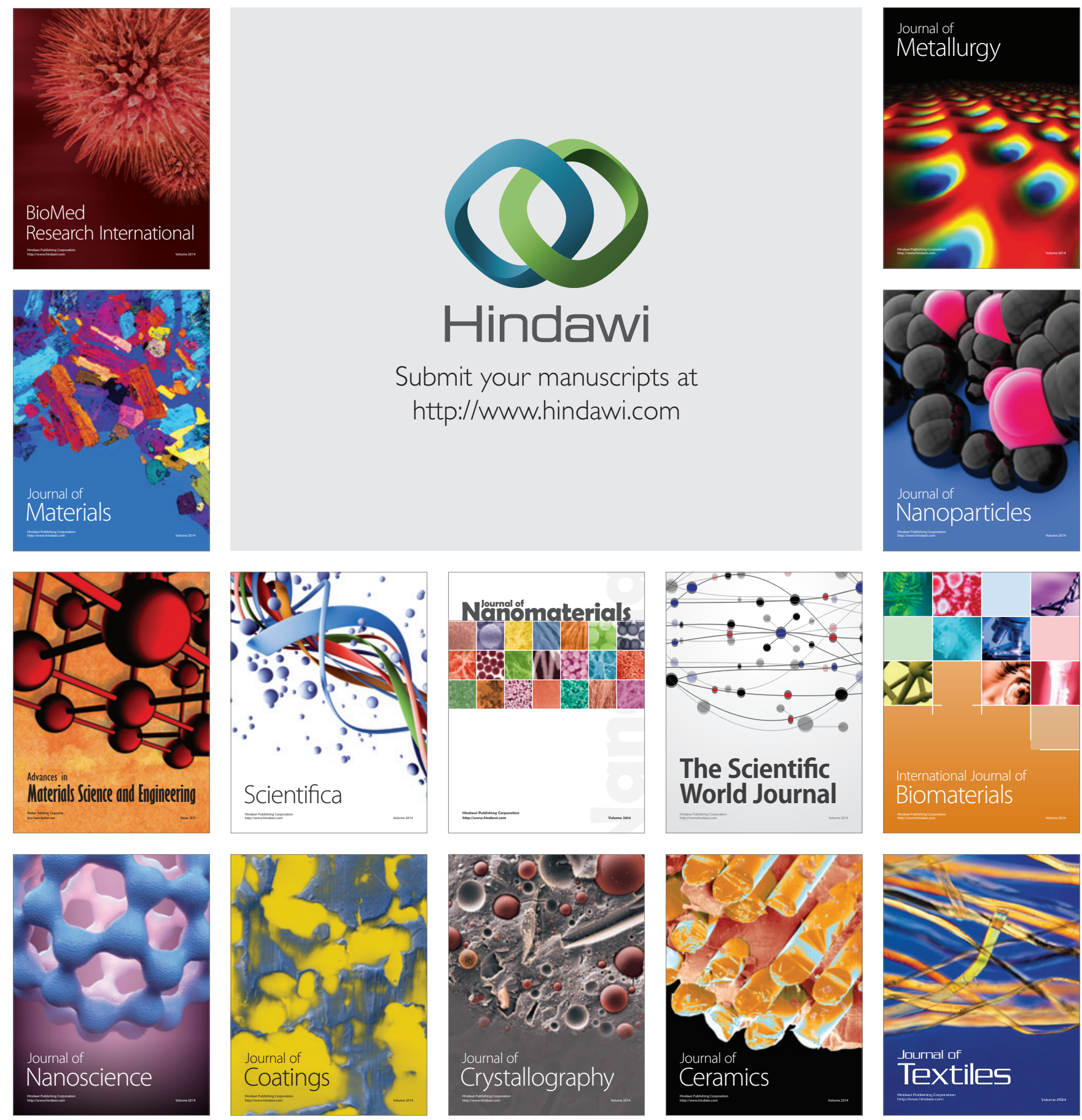